\title{
Dynamic Analysis of Beam Pumping Unit
}

\author{
Zhu Qingqing $^{1, a}$, Zeng Shixian ${ }^{1, b}$, Li Yuanyuan ${ }^{1, c}$ and Sun Qiang ${ }^{2, a}$ \\ ${ }^{1}$ Qingdao Huanghai College, Qingdao, China \\ ${ }^{2}$ China Offshore Oil Engineering (Qingdao) Co., Ltd. \\ 1,aZhuqq1225@163.com, 1,b12893317@qq.com, ${ }^{1, c} 568146084 @ q q . c o m$ \\ ${ }^{2, a}$ sq@mail.cooec.com.cn
}

\begin{abstract}
Beam pumping unit is the most important ground equipment of the sucker rod pumping system. According to the geometric relations and motion relations of the pumping four-bar linkage, the polished rod motion law is obtained. Based on the torque balance, the dynamic equations of each part for the beam pumping unit are established and output torque with crank shaft are derived, which provide a basis for system balance and condition monitoring.
\end{abstract}

Keywords: Beam pumping unit, Polished rod, Dynamic characteristics

\section{Introduction}

At present, there are two major categories of oil production methods in oilfield. One is commonly known as flowing oil-production using natural energy of oilfield to lift crude oil; another is called artificial lifting oil-production, which relies on artificial supplementary energy to lift the crude oil onto the ground because of the lack of natural energy supplement. Statistics shows, artificial lifting wells accounts for about $90 \%$ of the total wells in the world, and the sucker rod wells account for $90 \%$ of the artificial lifting wells. Obviously, rod pumping is the most wide mode of oil production. Beam pumping unit is the most widely used apparatus at home and abroad. It is very important to analyze the dynamic characteristics of the system.

\section{Kinematics analysis of beam pumping unit}

The motion model of beam pumping unit is established to find the rule of the polished rod displacement, velocity and acceleration as time changes and provide kinematic data for the load analysis and calculation of torque. Conventional beam pumping unit was studied as an example in this paper.

\section{Geometrical analysis}

The geometrical relations of four bar linkage mechanism of pumping unit must be obtained firstly. Fig. 1 is the body diagram of four-bar linkage for conventional beam pumping unit. For the convenience of analysis, define the positive direction of each angle in the graph as follows: (1) From the twelve o'clock position, crank angle $\theta$ take the clockwise direction as positive.(2) From the $O O_{1}$ position, reference angle $\theta_{2} 、 \theta_{3} 、 \theta_{4}$ of each bar take the counterclockwise direction as positive.Fig. 1 shows:

$$
\alpha=a \tan \left(\frac{I}{H}\right)
$$




$$
\begin{aligned}
& \theta_{2}=2 \pi-\theta+\alpha \\
& K=\sqrt{I^{2}+H^{2}}
\end{aligned}
$$

Geometric parameters of Fig.1 can be obtained from the above formulas. Further details was consulted in reference [2].

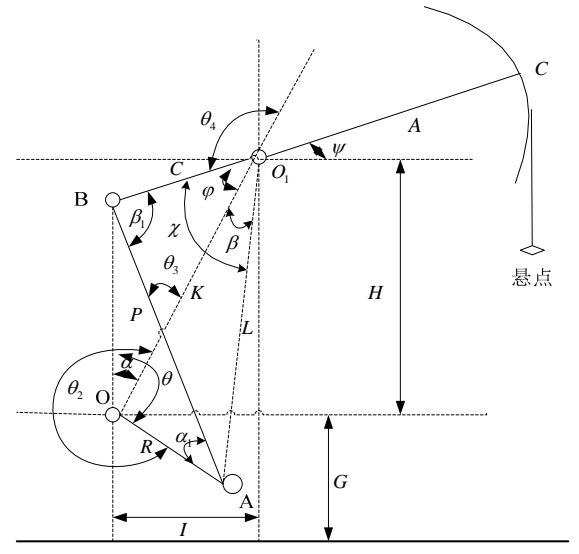

Fig.1 Body diagram of four-bar linkage for pumping unit

\section{Kinematic analysis}

According to the position relationship of each component in Fig.1, the vector relation is obtained as follows:

$$
\stackrel{1}{R}+\stackrel{1}{P}=\stackrel{1}{K}+\stackrel{1}{C}
$$

According to the derivation of time $t$ for both sides of the above equation, the angular velocity of linkage and beam is obtained as follows:

$$
\begin{aligned}
& \omega_{\mathrm{lg}}=-\theta_{3}=\frac{R \omega}{P} \cdot \frac{\sin \left(\theta_{4}-\theta_{2}\right)}{\sin \left(\theta_{3}-\theta_{4}\right)} \\
& \omega_{y l}=-\theta_{4}=\frac{R \omega}{C} \cdot \frac{\sin \left(\theta_{3}-\theta_{2}\right)}{\sin \left(\theta_{3}-\theta_{4}\right)}
\end{aligned}
$$

According to the derivation of time $\mathrm{t}$ for both sides of the above equations, the angular acceleration of linkage and beam $\theta_{3}, \theta_{4}$ is obtained as follows(at the assumption of uniform crank rotational speed, $\left.\theta_{2}=0\right)$ :

$$
\begin{aligned}
& a_{\mathrm{lg}}=\omega_{\mathrm{lg}}\left[\left(\omega_{y l}-\omega\right) \cot \left(\theta_{4}-\theta_{2}\right)-\left(\omega_{\mathrm{lg}}-\omega_{y l}\right) \cot \left(\theta_{3}-\theta_{4}\right)\right] \\
& a_{y l}=\omega_{y l}\left[\left(\omega-\omega_{\mathrm{lg}}\right) \cot \left(\theta_{2}-\theta_{3}\right)-\left(\omega_{\mathrm{lg}}-\omega_{y l}\right) \cot \left(\theta_{3}-\theta_{4}\right)\right]
\end{aligned}
$$

\section{Motion law of polished rod}

Take bottom “dead point”as the zero point of displacement, and upward direction as positive, the displacement of polished rod PR is obtained at any time as follows:

$$
P R=\left(\psi_{\max }-\phi\right) A
$$


Take polished rod upward motion as positive direction of displacement, the velocity and acceleration of polished rod are obtained respectively as follows:

$$
\left\{\begin{array}{l}
v_{c}=\theta_{4} \cdot A \\
a_{c}=\theta_{4} \cdot A
\end{array}\right.
$$

Taking conventional beam pumping unit CYJ10-3-53HB as an example, Fig.2 shows the movement of the polished rod of displacement, velocity and acceleration's rule with crank angle. Fig.3 shows the motion laws of the linkage and beam.

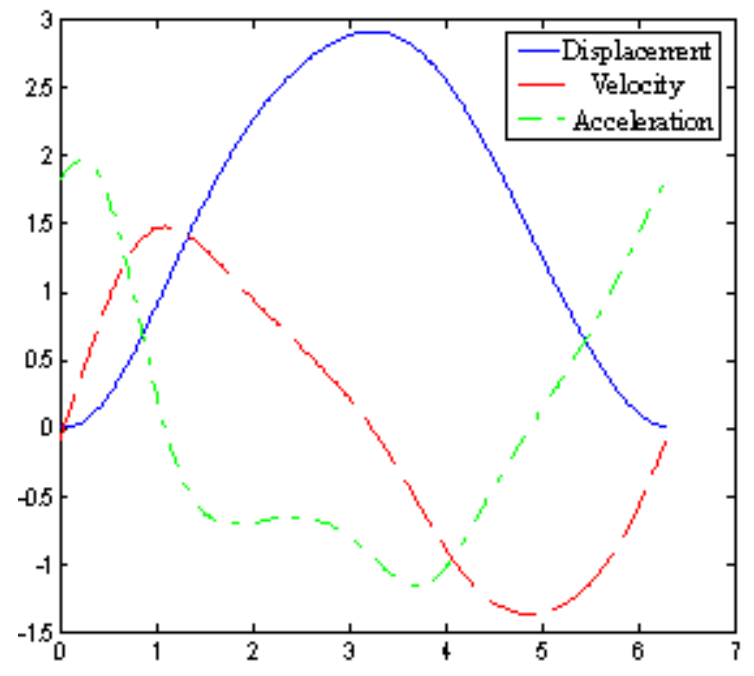

Fig.2 Motion law of polished rod
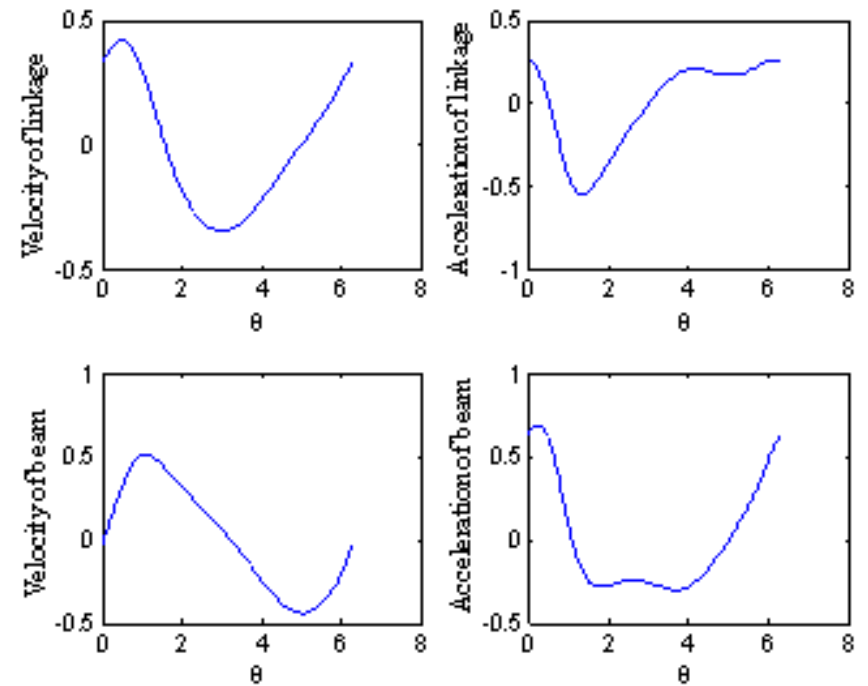

Fig.3 Motion laws of linkage and beam

\section{Dynamic analysis of beam pumping unit}

First, the dynamics parameters such as polished rod load are detailedly analyzed. Then, according to the load analysis of four bar linkage mechanism and the torque balance, the dynamic equations of each part for the beam pumping unit are established. The crank shaft torque is calculated by solving the dynamic equations of each component about polished rod load, which not only checks whether reducer casing is under normal torque conditions or not, but also checks and calculates the utilization of motor power ${ }^{[3]}$.

\section{Analysis of polished rod load of pumping units horsehead}

There are following several kinds of load on the polished rod when the pumping units is working $^{[4]}$ :

1. The weight of sucker rod with downward direction.

2. The weight of oil column on the piston (the plunger area minus the sucker rod area)in tubing with downward direction too.

3. The pressure of oil column for the bottom of plunger outside of the tubing with upward direction, whose value depends on the pump submergence.

4. The inertial load is generated by the movement of rod string and oil column. Theirs values are proportional to the acceleration of polished rod, but the effect of direction is contrary to the direction of the acceleration.

5. The oscillating load is generated by the movement of rod string and oil column, whose size and direction are changing.

6. The friction force between plunger and pump barrel, sucker rod and tubing, sucker rod and oil column, oil column and tubing, and the friction in liquid when oil flowing through traveling valve 
of oil pump, of which action directions are contrary to the direction sucker rod moves. The liquid friction of traveling valve is produced only during down stroke of pump and traveling valve opening, so action direction is always upward.

The above1,2,3 three loads are independent of the movement of sucker rod, called static load. The above4,5 two loads are associated with the movement of sucker rod, called dynamic load. The above 6 is associated with the movement of sucker rod too. In the case of straight well, less paraffin deposit of tubing and low viscosity of crude oil, the load is neglected generally because of a little proportion of all the applied loading, accounted for about 2-5\%.

\section{Stress analysis of beam}

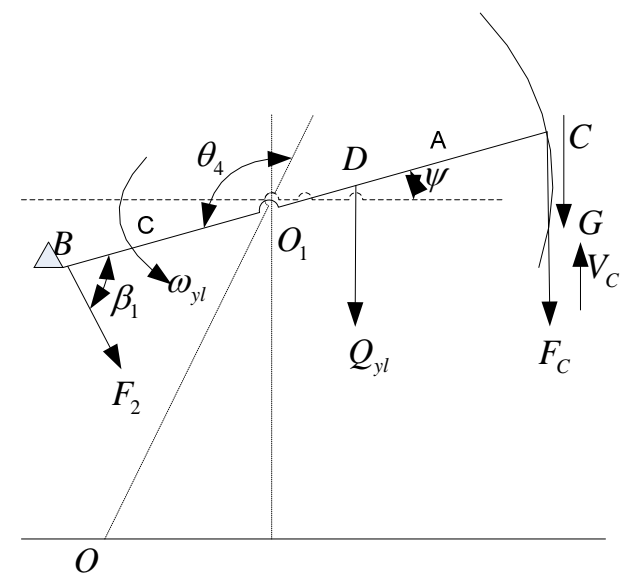

Fig.4 Diagrammatic sketch about stress analysis of beam

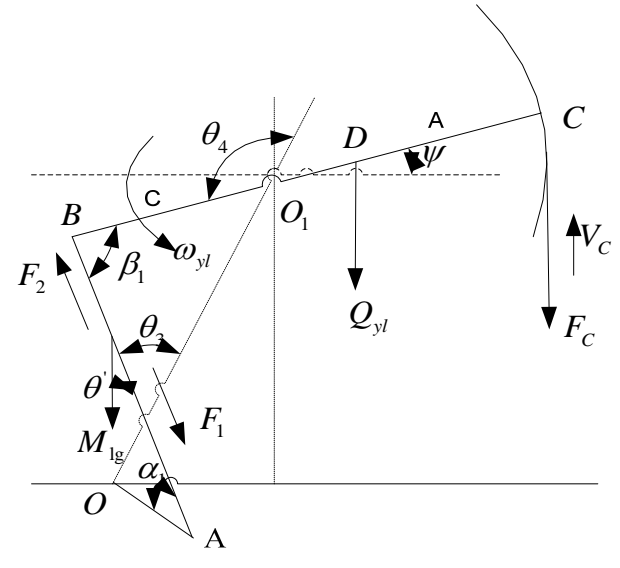

Fig.5 Diagrammatic sketch about stress analysis of linkage

During the beam's movement, stress analysis is shown in Fig.4. According to the moment balance:

$$
F_{2} \sin \beta_{1} \cdot C-G \cos \psi \cdot A-Q_{y l} \cos \psi \cdot \mid Q D D-F_{C} \cos \psi \cdot A-f_{o_{1}} \cdot \omega_{y l}=J_{y l} \cdot a_{y l}
$$

\section{Stress analysis of linkage}

During the linkage's movement, stress analysis is shown in Fig.5. According to Newton second law:

$$
F_{1}-F_{2}+M_{\mathrm{lg}} g \cos \theta^{\prime}=M_{\mathrm{lg}} C a_{y l}
$$

\section{Stress analysis of crank}

During the crank's movement, stress analysis is shown in Fig.6. According to the moment balance:

$$
T-F_{1} \sin \alpha_{1} \cdot|O R|+Q_{q b} \cos \left(\theta-\frac{\pi}{2}\right) \cdot|O R|+q_{q b} \cos \left(\theta-\frac{\pi}{2}\right) \cdot|\operatorname{Or}|-f_{o} \cdot \omega-f_{\mathrm{A}} \cdot\left(\omega-\omega_{\mathrm{g}}\right)=0
$$

The output torque of crank shaft is obtained by combining and solving the above equations.

$$
\begin{aligned}
T= & \frac{\sin \left(\theta_{3}-\theta_{2}\right)}{C \sin \left(\theta_{3}+\varphi\right)}\left[F_{C} \cdot A+J_{y l} \cdot a_{y l}-Q_{y l} \cos \left(\theta_{4}+\varphi\right) \cdot\left|O_{1} D\right|-G \cdot C^{2} \cdot a_{y l}\right. \\
& \left.+G \cdot C \cdot \cos \left(\theta_{4}+\varphi\right)\right]+Q_{q b}\left|O_{1} R\right| \cos \theta+q_{q b}\left|O_{1} r\right| \cos \theta
\end{aligned}
$$

Simulation study on the beam pumping unit CYJ5-2.5-26HB, The parameters of ground equipment are substituted in Formula(14) and the output torque of crank shaft is obtained, as shown in Fig.7. According to the crank balance criterion, the system is in equilibrium state ${ }^{[5]}$. 


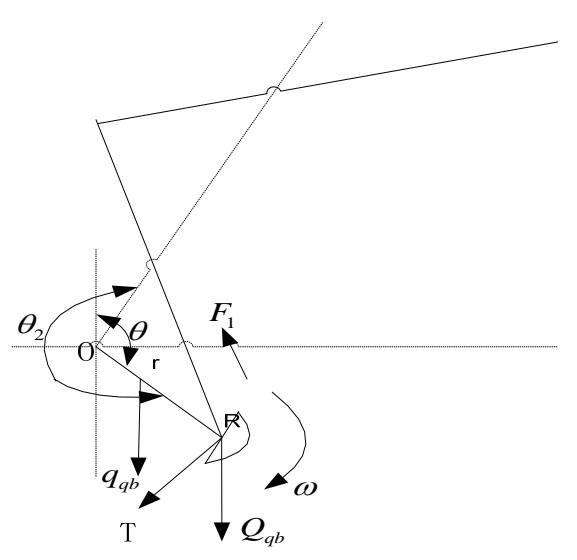

Fig.6 Diagrammatic sketch about stress analysis of crank

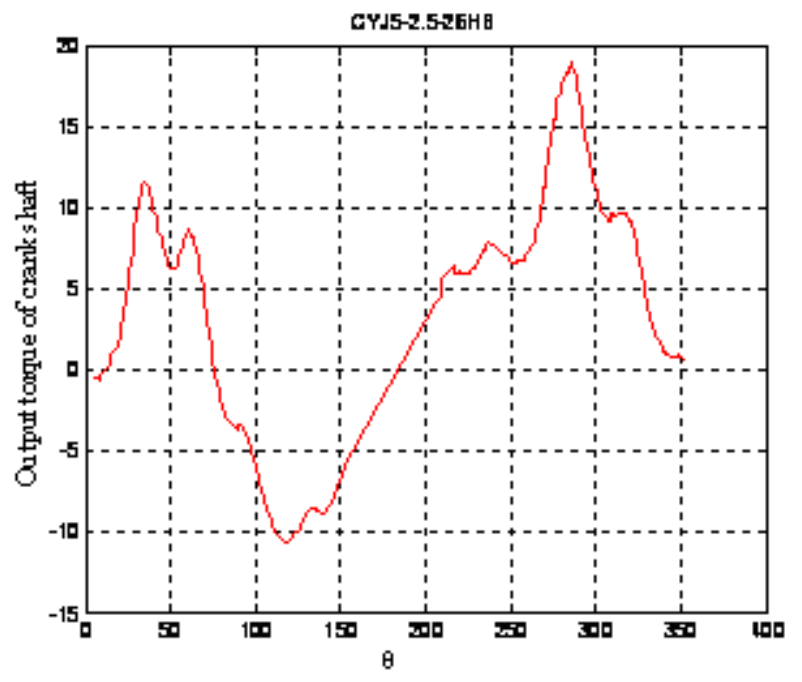

Fig.7 Simulation results about the output torque of crank shaft

\section{Brief summary}

Beam pumping unit is main equipment of sucker rod pumping system. It makes much sense to proceed with dynamics analysis. This paper proposes a new method that stress analysis on each component of the beam pumping unit and establishing dynamics model according to the moment balance, which provides the basis for the simulation of vibration characteristics of sucker rod string.

\section{Symbol Description}

$R$-Crank radius, $\mathrm{m} ; \quad P$-Length of base stem, $\mathrm{m} ; \quad C$-Length of beam latter arm, $\mathrm{m}$;

A-Length of beam forearm, $\mathrm{m}$; $I$-Horizontal projection of base stem, m;

$H$-Height between support bearing centre and output shaft centre of gearbox, m;

$F_{2}$-Pull between linkage and beam, $\mathrm{N}$;

$G$-Unbalanced weigh of the structure, $\mathrm{N} ; \quad G=\frac{q_{\mathrm{lg}} C-Q_{y l}\left|O_{1} D\right|}{A}$

$Q_{y l}$-Weight of beam, kg; $F_{C}$-Polished rod load, N;

$J_{y l}$-Moment of inertia about beam, $\mathrm{kg} \cdot \mathrm{m}^{2}$;

$\beta_{1}$-Angle between $\mathrm{C}$ and $\mathrm{P}$, anticlockwise is positive direction, rad;

$\psi$-Angle between beam and the ground level line, anticlockwise is positive direction, rad;

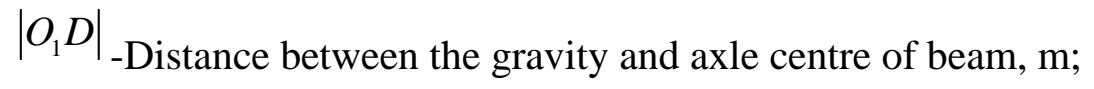

$F_{1}$ _Pull between the crank and linkage,N; $M_{\mathrm{lg}}$-Weight of the linkage, kg;

$\theta^{\prime}$-Angle between linkage and the ground vertical line, anticlockwise is positive direction, rad; 
$T$-Output torque of crank shaft, $N \cdot m ; Q_{q b}$-Weight of crankshaft counterweight, N;

$q_{q b}$-Weight of the crank, N;

$|O R|$-Distance between the gravity of crankshaft counterbalance and rotation center $O$ of crank, m; $\mid$ Or|-Distance between the gravity and rotation center $O$ about crank, m.

\section{References}

[1] Gabor Takacs, Laszlo Kis and Adam Koncz. The calculation of gearbox torque components on sucker-rod pumping units using dynamometer card data. J petrol Explor Prod Technol. Vol.6 101-110 (2016)

[2] Gibbs SG. Rod pumping. Modern methords of design, diagnosis and surveillence. Book Masters Inc,. Ashland (2012)

[3] Gibbs SG. Computing gearbox torque and motor loading for beam pumping units with consideration of inertia effects. JPT 27:1153-1159 (1975)

[4] Lea JF. Artificial lift selection. Chapter 10 in SPE Petroleum engineering handbook, Vol.IV. Society of Petroleum Engineers, Dallas (2007)

[5] Himanshu Chaudhary, Subir Kumar Saha. Balancing of four-bar linkages using maximum recursive dynamic algorithm [J]. Mechanism and Machine Theory, 2007:42 